Exicke's Comfx, 1895-1908. - The Monthly Notices for March (vol. lxx., No. 5, p. 429) contains a discussion by Dr. Backlund of the motion, brightness, \&c., of Encke's comet during the period I $895^{-1908}$. In the first place, he deduces elements fitting the observations of 1895 , 190I, and IgO4, and shows that the acceleration of the mean motion was not constant during the period under discussion. This leads to a discussion of the various causes which might produce the diminution observed, and of the probable time at which such causes, or cause, were, or was, effective. Excluding solar electrical forces, it seems probable that the resistance encountered is a meteoric swarm in the neighbourhood of perihelion, and the decrease of the acceleration must be attributed rather to the diminution of the density of the resisting medium than to changes in the comet itself. If, however, the variation of the acceleration is held to be actually connected with the maxima of solar activity, tangential electrical forces are admissible in explaining it, and the problem becomes indeterminate.

Various causes of the comet's fluctuations in brightness, e.g. an alteration in shape, and therefore in surface presented, produced by the solar tidal action, are discussed, but no explanation is entirely satisfactory, and the question is left open.

Dr. Backlund then investigates the relation between Wolf's comet of 1907 and Encke's comet, and the possibility of capture by Jupiter. Whilst not proving that the comet was captured, he shows the possibility of such capture having taken place within the past 5700 years.

The Spectra of the Major Planets.-In Bulletin No. 42 of the Lowell Observatory Dr. V. M. Slipher publishes further descriptions and reproductions of the spectra of the major planets. The photographs were taken with plates especially sensitised for the red end of the spectrum, and show a wealth of detail between $D$ and A. Comparative exposures on the south equatorial dark belt and the bright equatorial region of Jupiter indicate no reason for supposing that the darker portions of the planet are those lying the deeper. The spectrum of Saturn is generally similar to that of Jupiter, but there is a strong band in the latter at $\lambda 646$ which is absent, or nearly so, in the former; as the others are of the same intensity, this points to the existence of a constituent in Jupiter's atmosphere which is absent in that of Saturn. No trace of the planetary bands is found in the spectra of Saturn's rings, and there is no indication of any atmosphere about the rings.

A comparison of the spectra of the four major planets shows that in Neptune all the bands seen in the other three are intensified, except that at $\lambda 646$, which appears to be peculiar to Jupiter. The evidence for hydrogen absorption in the atmospheres of Uranus and Neptune is very slight, and the intensification of $\mathrm{C}$ and $\mathrm{F}$ is not copied by the hydrogen bands at $\lambda \lambda 434 \mathrm{I}$ and 4102 , so far as an ordinary eve examination can determine, so that, at the best, the identity can only be considered probable. Of the other bands photographed scarcely anything is known, but it is shown that the very strong band at $\lambda 619$ is not identical with one in the spectra of red stars, as is sometimes stated.

The Intrinsic Brilliancy of the Sun.-In a previous paper Dr. Nordmann estimated that the intrinsic brilliancy of the sun was 319,000 decimal candles per sq. $\mathrm{cm}$. (Nature, March 3, p. 29), but he now finds that one of his data, owing to an ambiguity in Müller's text, is incorrect. He has, therefore. re-calculated his value, and gives, in No. ${ }^{3} 3$ of the Comptes rendus (March 29), 100,500 decimal candles per sq. $\mathrm{cm}$.

\section{THE CARNEGIE INSTITUTION OF} WASHINGTON.

THE eighth annual report of the Carnegie Institution of Washington, describing the work of the institution during the year 1909, has now been published. It is a well-illustrated volume of 259 pages, dealing with the work of administration, the investigations carried out under the auspices of the institution, the various publications, the expenditure recommended for IgIo, and additional sugges- tions. Subjoined are extracts from the report of the president of the institution upon the progress of the difterent scientific departments.

Among the more important events of the year are the completion of the administration building in Washington the establishment and active operation of the observatory of the department of meridian astrometry in Argentina, the construction and putting into commission of the nonmagnetic ship Carnegie of the department of terrestrial magnetism, and the inauguration of the project for the publication of an edition of the master-works on international law. Attention is directed to the fact that with these, and with the previously established larger enterprises under way, the accumulated income of the institution has been exhausted, and that there will be no room for further expansion under current income in the immediate future.

In the last annual report a summary statement of the work of the institution up to October $3 \mathrm{I}$, 1908, was given. A more detailed study of the scope and geographical range of this work shows that investigations have been carried on under the auspices of the institution in more than thirty different fields of research, and that these investigations have extended to more than forty different countries. The total number of volumes of publications issued directly by the institution is I4I, with an aggregate of about 35,000 pages of printed matter. For the larger departments of investigation there are now provided two astronomical observatories, five laboratories, and one ship. A complete list of the equipments of these establishments includes fiftyeight buildings and eight smaller craft in addition to the ship Carnegie. The total amount of funds granted for expenditure is $864,000 l$. The total amount expended is $825,900 l$.

At the date of the preceding annual report the department of meridian astrometry was engaged in the construction of a temporary observatory at San Luis, Argentina. The instrumental equipment for this was shipped from the Dudley Observatory, Albany, N.Y., in December, 1908. After safe transportation to San Luis, the constants of the meridian transit, the principal instrument used, were carefully re-determined, proving to the highest order of precision that this instrument suffered no injury in transshipment. With this indispensable preliminary investigation completed, the work of stellar observation was begun in April. ryog, and is now going on at a rapid rate.

The following list shows the departments of investigation to which the larger grants were made by the trustees and the amounts allotted from those grants by the executive committee during the year :-

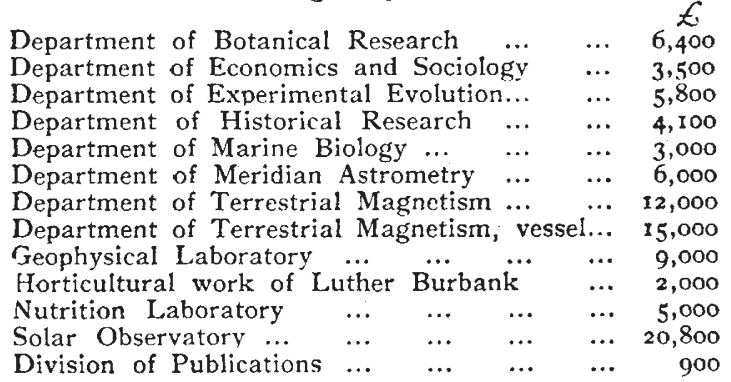

The various investigations of the botanical research department have been successfully continued during the past year. Among these, the experiments of the director in the production of mutants in plants seem destined to play a fundamental role in the determination of the absorbing biological question of the derivation of species. Equally important in this same line are the experiments with beetles of Prof. Tower, for which vivaria are now maintained at the Desert Laboratory at Tucson and at the Marine Biological Laboratory at Dry Tortugas, Florida. The work of the department of experimental evolution presents a double interest in furnishing evidences at once of the evolution of organic forms and of the evolution of a science. The history of biological science, like the history of most sciences in their earlier stages, has been, and still is, marred to some extent by heated controversy. But all this is destined to disappear with the rise of biology

NO. 2 I I 2 , VOL. 83] 
to the plane of quantitative determination. It is on this plane that the department in question is seeking, with capital initial success, to carry on its investigations. The publications of the department already issued are reckoned among the most important of recent contributions in this large field of research.

The work of the geophysical laboratory proceeds by means of some of the most recent methods and appliances of research, and hence its aims and lines of investigation, like those of all new sciences, present to the public more or less of obscurities of interpretation and obstacles to ready appreciation. The researches of the laboratory afford another instance of the normal evolution of a science from the observational and descriptive stage to the higher level of measurement and calculation. That geology and mineralogy will be much advanced by such researches is now recognised and attested by eminent specialists. Indeed, the definitive results already attained by members of the laboratory staff are now finding their way into the elementary as well as into the more technical literature of those sciences. The equipment of the laboratory has received an important addition during the year in apparatus for subjecting materials under observation to high pressures and temperatures, either simultaneously or separately. This apparatus, developed by Dr. A. Ludwig, research associate of the department for the year, will give pressures up to 17,000 atmospheres, or $250,000 \mathrm{lb}$. per square inch.

The Tortugas laboratory of the department of marine biology is proving highly effective as a centre for research by a wide range of specialists. Eight associate investigators have availed themselves of the opportunities afforded by the department during the past season, and the results of their studies are now in preparation for publication as contributions to science from the laboratory. It is of interest to note the advent of quantitative investigations here as well as elsewhere in the advancing biological sciences.

The apparatus of the nutrition laboratory proves highly effective, and the experiments already made. on pathological as well as normal subjects, fully justify the confident expectations hitherto entertained with respect to this line of research. Many additions have been made during the year to the equipment of the laboratory. Among these are a bed-calorimeter into which a recumbent patient may enter with ease and safety; a portable respiration apparatus which may be applied readily to a patient reclining on a cot while his respiratory action is accurately determined; and an automatic temperature register, which will give a continuous record of temperature changes in the calorimeters to which it is applied.

The achievements already attained in the development of novel methods and effective apparatus for studies of the sun, and the additions to our knowledge of solar physics already made at the solar observatory, not only justify the predictions of its founders, but warrant the anticipation of still more important contributions to astrophysics in the near future. Work of investigation and work of construction have proceeded simultaneously during the year, both at the observatory site on Mount Wilson and at the shops and physical laboratory in Pasadena. The 6o-inch equatorial reflecting telescope, the installation of which was completed a year ago, has been tested during the past year and proved to be of unequalled excellence, whether used as a visual or as a photographic instrument. Its optical perfection and its wide range of applicability make it a noteworthy contribution to progress in observational astronomy. The 150 -foot tower telescope, authorised by the budget of the current year, is in a forward state of construction, and will soon become one of the most effective units in the telescope battery of the observatory. The discovery of the existence of the Zeeman effect in the sun, announced by the director a year and a half aoo, has been confirmed and extended in its application to further interoretation of the nature of sun-spots, as well as to researches into the more recondite electromagnetic properties shown by the sun. Closely connected, apparently, with these properties are the major and minor "magnetic storms" to which the earth's magnetism is subject. now of special interest alike to the staff of the solar observatory and to the staff of the department of terrestrial magnetism. It may suffice here to record only nne other item of interest, namely, the failure, thus far, of the manufacturers of glass at St. Gobain, France, to furnish a satisfactory disc for the roo-inch Hooker telescope. The disc reported as en route for delivery a yeat ago proved so defective that it had to be rejected. The manufacturers are still confident, however, that they can meet the requirements, and it is hoped that through the collaboration of Prof. Ritchey, of the observatory staff, who has spent some months at St. Gobain during the year, a satisfactory disc may be ultimately secured.

The field-work of the terrestrial magnetism department has gone forward with dispatch. Surveys have been carried on in fifteen different countries distributed over four different continents. The routes traversed by the observers will give a large aggregate of data from hitherto littleknown or unexplored regions. Thus Mr. Sowers has obtained observations at intervals along a route extending from eastern China west across China and Chinese Turkestan, and thence south to Bombay, India; Prof. Beattie, research associate of the department, has completed a survey from Cape Town to Cairo; Mr. Pearpleted a surect measurements in Persia, Beluchistan, Arabia, Turkey, and Russia; while other observers have been equally active in South America, Central America, and British America.

The publication of sixteen volumes of researches has been authorised by the executive committee during the year at an aggregate estimated cost of $5^{8} 4 \mathrm{ol}$.

\section{RECENT WORK OF GEOLOGICAL SURVEYS.}

$$
\text { III.-CANADA. }
$$

THE Geological Survey Branch of the Canadian Department of Mines continues to issue colour-printed geological maps at an extremely moderate price, as well as numerous mining plans on a large scale. We note that "individual maps or reports will be furnished free to bona fide Canadian applicants."

The Mines branch deals in its reports with technical matters relating to ore-deposits, the occurrence of which matters relating to the Dominion. but its memoirs cannot means so much to the Dominion; but Fritz Cirkel's report be neglected by the geologist. Mr. Fritz Cirkel's report
on the chrome iron ore deposits in eastern Quebec (Igog) thus contains an interesting account of the serpentines of Che chromite occurs in those of Cambrian Cancer serpentines appear, so age, while the earlier serpentines appear, so far, an with ductive. The Cambrian serpentines are associated with diorite, and are regarded (p. 18 ) as alteration-products of an olivine-gabbro. Their non-aluminous character, as shown in the typical analysis given, would lead one to assume that considerable differentiation had gone on in assume that conside that the serpentine was at one time the basic series, and that than a gabbro. This is probably the author's view, as stated on p. 87 . The chromite is irregularly distributed in pockets, a provolking arrangeirregularly distributed in pockets, a pre of the occurrences ment for the miner, and reminding one in the Dun Mountain district of New Zealand the world at port, with its review of chromite ores in the world at large, is of far more than local value, and well referred in and illustrated. Mr. F. Hille's report, on some ironore deposits in Thunder Bay and Rainy River districts, Ontario dwells on the possibility of using peat-coke, Ontario, dwells on the possiocess, as a fuel for smeltmanufactured by the Many provinces of Canada are rich in peat, poor in ing. Many provinces of Canada are rich dealt with in the wood, and destitute of coalite and hæmatite, and a magnetic survey has been used in the detection of the former.

The recent reports of the Canadian Geological Survey Branch include one by $\mathrm{Mr}$. W. H. Collins on Gowganda Mining Division, Ontario (1909), with a very large geological map on the scale of one inch to one mile. The district described lies atong the Montreal River, west of the Quebec border, and is being invaded by a rush of prospectors, owing to the discovery of silver cobalt ores similar to those that have made the reputation of Cobalt. The valuable veins occupy large fissures in quartz-diabase, which is intrusive in Huronian sediments. The author traces a magmatic gradation from the diabase into an aplite intimately associated with it (p. 33). The illustra-

1 The second article appeared in NATURE of February ro.

$$
\text { NO. } 2 \text { I I } 2, \text { VOL. 83] }
$$

